\title{
Study of the Influence of Multiple Intelligences and the use of Soft Skills in Project Write-up among IT and Non-IT Students: A Research Paper
}

\author{
Mahendrenath Motah \\ University of Technology, Mauritius \\ Pointe aux Sables, Mauritius
}

mmotah@utm.intnet.mu

\begin{abstract}
The present work is a follow-up of the papers presented at the Northern Arizona University, USA - "Accommodating soft skills in Software project Management" and the one presented at Salford University, Manchester, UK - " The ontogeny of memory of learning: Natural Intelligence versus Artificial Intelligence in Information Technology Education". Several interrogations cropped up during and after the presentation of the second paper, particularly on the conclusions, if any, that could have been drawn on the effects of soft skills, intelligence and intelligences; and if the next step would be to further investigate the impact of these on Information Technology Education. The impression that there was an urgent need to delve deeper into these factors and to find out their importance from the point of view of information technology education and other non IT fields lingered on for an appreciable length of time. In order to reply to the various unavoidable questions that arose from an analysis of the hypothetical aspects introduced in the above mentioned papers, we have tried to look into the influence of the factors related to the concepts of soft skills and intelligence in educational endeavours. In order to have an in-depth appreciation of the importance of these factors, we have solicited the involvement of both IT and Non-IT students reading in the fields of Administration and Management and Information Technology. Finding out the importance and the influence of soft skills and intelligence or intelligences became an obsession which resulted in an interesting and passionate exercise with the involvement of nearly two hundred students. We believe that, sharing the results of our findings with other colleagues would arouse further interests and trigger other more interesting research in the field.
\end{abstract}

Keywords: Intelligence, multiple Intelligences, soft skills, project write-up, IT and Non-IT students. Information Technology Education

Material published as part of this publication, either on-line or in print, is copyrighted by the Informing Science Institute. Permission to make digital or paper copy of part or all of these works for personal or classroom use is granted without fee provided that the copies are not made or distributed for profit or commercial advantage AND that copies 1) bear this notice in full and 2) give the full citation on the first page. It is permissible to abstract these works so long as credit is given. To copy in all other cases or to republish or to post on a server or to redistribute to lists requires specific permission and payment of a fee. Contact Publisher@InformingScience.org to request redistribution permission.

\section{Introduction}

The purpose of this study is to examine the importance of multiple intelligences and the use of soft skills in project write-up and presentation among IT and non-IT students. The theme is viewed as important to all students and teachers. Hence the research aims at providing both learners and teachers an insight on 
the influence of factors such as communication, team work, leadership, stress management, time management, trustworthiness, conflict management, and organisational effectiveness, which we call soft skills as opposed to hard skills, described as a science (Belzer,2004) comprising of processes, tools and techniques applied to projects. Furthermore, we also wanted to find out how the theory of multiple intelligences which comprises functions of perceptions, cognition, assimilation, adaptation, complexity, and competency and understanding (Armstrong, 1984; Mayer and Cobb, 2000), could apply to our field of research. We have also tried to investigate how the eight multiple intelligences proposed by Gardner (1999), which is employed in a variety of settings, including everyday life, educational and work settings, influenced the students in their work. The MI as proposed by Dr. Howard Gardner is as follows: linguistic, logical-mathematical, spatial, bodily-kinaesthetic, musical, interpersonal, intrapersonal and natural intelligences. It appears that the understanding and use of soft skills and the judicious choice of the appropriate type of intelligence are crucial to the successful completion of tasks related to educational assignments. In order to satisfy our growing interest on the importance of these two important dimensions, we decided to work out two questionnaires, one based on eight factors which have been highlighted in the paper " Accommodating soft skills in software project management" as mentioned earlier; and another one on the eight different intelligences as proposed by Gardner (1999).

\section{Design and Methodology}

Students studying at the School of Public Sector Policy and Management; the School of Business Informatics and Software Engineering of the University of Technology, Mauritius, and other students reading in public and private educational institutions were asked to fill out questionnaires on the importance of intelligence or intelligences and the use of soft skills in the preparation and presentation of their course assignments and their final project/dissertation. The two questionnaires were distributed to 125 Non-IT students, of which 115 (92\%) responded; and to 90 IT students, of which $72(64.8 \%)$ responded. The data obtained was statistically analysed using the SPSS tool. The findings from the data obtained are presented at a later stage in this research paper.

\section{Research Findings}

The findings provides information on how IT students, that is, those students following undergraduate and post graduate studies in fields where Information Technology is a dominant feature, and the major field of study, use soft skills and how MI influence their studies. On the other hand it provides information on how Non-IT students, that is, those students who are reading on undergraduate and post graduate programmes in the field of Administration and Management use soft skills, and MI in dealing with the demands of their area of study. The results of the study can help lecturers in their work, by providing them with knowledge on the types of intelligences they can encourage students to develop, and at the same time help those students to enhance the desirable soft skills required for the successful completion of their studies.

\section{Research Limitations}

We still need to probe further to find out the relationship between soft skills and the type of intelligence used by students in their endeavour to compete successfully in their respective field of study. Further, we did not make gender distinction as both male and female students follow the same programme and have the same modules and the same assignments. There seem to be no gender discrimination in any aspect of the educational lifestyles of those we have solicited for the research. Another dimension which may have some influence, and which has not been investigated is the age of the participants. Can age influence the choice of soft skills and the use of a distinct type of intelligence? This could be the theme of the next paper. 


\section{Originality}

Papers dealing with soft skills, intelligence, multiple intelligences, and emotional intelligence as separate topics are quite numerous, we are tempted to believe that the present paper is, as far as our investigation is concerned, one of the few that attempts to bring forth a relationship between soft skills and multiple intelligences among students reading in different fields: IT and Non-IT related fields.

\section{Literature Review}

\section{Soft Skills}

Although soft skills refer to a wide range of abilities including flexibility, creativity, problem solving skills, listening skills, we have chosen those which have been found to be relevant to our area of interest, namely: communication skills, team building skills, leadership skills, stress management skills, time management skills, conflict management skills, trustworthiness and organisational effectiveness.

\section{Communication skills}

Communication is the process of a sender transmitting a message to a receiver with mutual understanding; and the goals of communication are to influence, inform, and/or to express feelings. Hence, the importance of effective communication cannot be minimised as the goals of communication often affects our behaviour (R.N.Lussier, 1990). As communication is considered to be the structure on which human relations are built. If you are polite and friendly, chances are that others will in turn behave in a similar way. However, if you are rude the other may retaliate, and thus may affect human relations either positively or negatively depending on the type of communication behaviour people indulge in.

\section{Team building skills}

Team building is a technique designed to help work groups operate more effectively. These include various aspects such as clarifying the objectives of the team and team members; identifying problems; developing skills; utilising available resources; developing working relationships based on trust. Team building encourages team members to examine how they work together, identify their weaknesses, and develop more effective ways of cooperating. (Newstrom J.W. \& Davis K. 2002).

\section{Leadership skills}

Leadership is the process of influencing and supporting others to work enthusiastically towards achieving objectives. In order to be able to do this, leaders should possess Technical Skills (knowledge of and ability in any type of process or technique); Human Skills (ability to work effectively with people and to build teamwork); and Conceptual Skills (ability to think in terms of models, frameworks, and broad relationships, such as long-range plans).Recent developments in the area is linked to the work of Daniel Goleman (1995), who states that "effective leaders are alike in one crucial way: they all have a high degree of emotional intelligence". The five components of EI being - self-awareness, self- regulation, motivation, empathy and social skills.

\section{Stress management skills}

Stress can affect both physical and mental health. This is true among students who are sometimes confronted with undue pressure, when they have to meet deadlines in the submission of their assignments, projects or dissertations. Managing stress through different techniques and pro- 
grammes: relaxation, exercises, diet, biofeedback, social support, personal wellness, counselling and others. ( Newstrom \& Davis, 2002).

\section{Time management skills}

The ability to effectively manage time through prioritising and identifying and eliminating time wasters is the key to time management. Its one of the most important skills which students, like the ones we have identified for the research, need the most.

\section{Conflict management skills}

There are two types of conflict, one which can be classified as constructive or functional or destructive or dysfunctional; a second way of classifying conflict is to see it as intra-individual, interpersonal, inter-group, intra-group or inter-organisational. To resolve these types of conflict, one must identify their sources which can be due to individual differences, information sources, different objectives and environmental factors. (Lussier, 1990). Conflict resolution skills can prevent behaviours of team members from degenerating into irreconcilable situations that may prohibit them from ever working together productively again. (Newstrom \& Davis, 2002)

\section{Trustworthiness}

Continuing relationship requires some degree of trust - defined as the capacity to depend on each other's word and actions. (Newstrom \& Davis, 2002). The existence and promotion of trust among students can only bring more benefits to the students themselves, and can also contribute towards avoiding conflicts. Trust is the basic requirement that can ensure the success of any human enterprise. (Sukhoo, Barnard, Eloff, Van der Poll, \& Motah, 2005)

\section{Organisational effectivenes}

Organizations where people continually expand their capacity to create the results they truly desire, where new and expansive patterns of thinking are nurtured, where collective aspirations are set free, and where people are continually learning how to learn together" (Senge 1990).

It is believed that organisational effectiveness is achieved by working all human system variables together in a balanced way. By doing this, the organisation becomes an effective organisation and a learning organisation. When an organisation becomes a learning organisation, it takes an institutional permanence, and acceptable modes of behaviour become self evident to its members. Such shared meaning held by members of the organisation contributes to the establishment and reinforcement of organisational culture. As a six-year old organisation, we are in the construction phase, and as such, we are in the process of establishing and reinforcing a positive organisational culture. We are, (as proposed by Farago\& Skyrme, 1995) giving due consideration to:

"Innovation and risk taking, attention to detail, people orientation, team orientation, outcome orientation, stability and positive aggressiveness".

\section{Multiple Intelligences}

As humans, our life is determined and influenced by various dimensions: a biological inheritance and physical appearance that distinguish us from other living beings; a psychological make-up which determines our mental, emotional, linguistic, behavioural and moral aspects; a social need which affects all aspects of our existence and lifestyle; and a spiritual dimension which helps us to distinguish right and wrong. (Motah, 2006)The most important and most prized possession is intelligence, yet it is a concept that even the most intelligent people ha not been able to agree on (Santrock, 2000). Dr Howard Gardner, professor of education at Harvard University, developed the theory of multiple intelligences in 1983 . The theory propounded that the traditional notion of 
intelligence, based on IQ testing, is far too limited. He instead proposes eight different intelligences to account for a broader range of human potential in children and adults. Gardner proposed the following eight MI which are employed in a variety of ways and a variety of settings, including work and educational settings. We have chosen the MI as proposed by Dr. Gardner for this paper and a questionnaire comprising questions investigating how these intelligences are interactive and how they work together was prepared and presented to both IT and Non IT students. The following eight intelligences were proposed:

\section{Linguistic intelligence}

Linguistic intelligence has to do with the capacity to use words spoken or written when communicating (Gardner, 1983). Specifically linguistic intelligence helps to display a facility with words and languages and indicates the use of syntax, structure, semantics and the meaning of language. People with linguistic intelligence tend to learn best by reading, taking notes, and listening to lectures, and via discussion and debate (Gardner, 1993), they are also frequently skilled at explaining and speaking. Those with linguistic intelligence have high verbal memory and recall and an ability to understand and manipulate syntax and structure. (Gardner, 1993)

\section{Logical-mathematical intelligence}

This type of intelligence has to do with inductive and deductive reasoning, and mathematical concepts. Definition of the logical -mathematical intelligence lays emphasis on reasoning capabilities, abstract pattern recognition, scientific thinking and investigation, and the ability to perform complex calculations. This intelligence indicates the ability to use and understand numbers and apply reasoning skills to explain relationships and abstractions.

\section{Spatial intelligence}

Spatial intelligence deals with the perception of visual and spatial world. People with strong visual-spatial intelligence are typically very good at visualizing and mentally manipulating objects. Those with visual-spatial intelligence also generally have a very good sense of direction and may also have very good hand-eye coordination. They possess the capacity to transform their perceptions into form, colour, space and relationships. (Armstrong, 1994). They also have the ability to form mental images of concepts and of their personal experiences and to transform these images into personal meaning and applications. .

\section{Bodily-kinaesthetic intelligence}

This intelligence helps people to acquire the expertise in using the whole body to express ideas and feelings, and the ability to building and making things. They often learn best by physically doing something, rather than reading or hearing about it. Those with strong bodily-kinesthetic intelligence seem to remember things through their body, rather than through words (verbal memory) or images (visual memory). They benefit from working with others in experiential situations, which allows for nonverbal implications rather than verbal communication. (Gardner, 1999).

\section{Musical intelligence}

This intelligence is built around the use of rhythms, music, and sounds to illustrate and communicate creative thinking. Those who have a high level of musical-rhythmic intelligence display greater sensitivity to sounds, rhythms, and music. Since there is a strong aural component to this intelligence, those who are strongest in it may learn best via lecture and oral stimulations. 
In addition, they will often use rhythms to learn and memorize information, and may work best with background soft music playing. (Gardner, 1993)

\section{Interpersonal intelligence}

People in this category are likely to indulge in and foster successful relationships, and are characterized by their sensitivity to others' moods, feelings, temperaments, and motivations and their ability to cooperate in order to work as a group. They can communicate effectively and empathize easily with others when working in groups, and may be either leaders or followers. (Gardner, 1993).They communicate effectively and possess the ability to persuade others; they typically learn best by working with others and often enjoy discussion and debate. They are attentive to nonverbal factors such as facial expressions, bodily gestures and voice.

\section{Intrapersonal intelligence}

Those who possess this intelligence are those who are believed to have more self-knowledge and tend to be more introspective, and cognitively and consciously self-aware, and prefer to work alone. Their self-awareness makes them capable of understanding their own emotions, goals, and motivations. They learn best when allowed to concentrate on the subject by themselves. (Gardner, 1999).There is often a high level of perfectionism associated with this intelligence, and tends to be aware of their personal strengths and weaknesses.

\section{Naturalistic intelligence}

It is believed that this is the newest of the intelligences, and concerns people who have the capacity to recognise and make distinctions between the natural and the artificial dimensions of things in the world. Those with it are said to have greater sensitivity to nature and their place within it, the ability to nurture and grow things, and greater ease in caring for, taming, and interacting with animals. They are also good at recognizing and classifying different species. (Gardner, 1999)

\section{Research Findings}

\section{Use of Multiple Intelligences}

The results obtained from the analysis of data using SPSS are as follows:

Figure 1 shows the types of intelligence used by IT and Non-IT students when they are working out their projects/assignments/dissertations. The category indicates the type of intelligence;
A - Linguistic intelligence.
E - Musical intelligence
B - Logical-Mathematical intelligence.
$\mathrm{F}$ - Interpersonal intelligence
C - Spatial intelligence.
$\mathrm{G}$ - Intrapersonal intelligence
D - Body-kinesthetic intelligence
$\mathrm{H}$ - Naturalistic intelligence

It appears that Non-IT students use more linguistic, interpersonal and intrapersonal intelligences more than their IT counterparts; while the IT students make use of logical- mathematical, spatial, body-kinesthetic and musical intelligences in their work in the field of information technology. It seems evident that the type of intelligences required for the preparation, completion and submission of projects and assignments in the field of information technology will require those abilities related to the technical aspects of this field of study. What comes as unexpected is the use of a high percentage of body-kinesthetic intelligence and musical intelligence. The low per- 


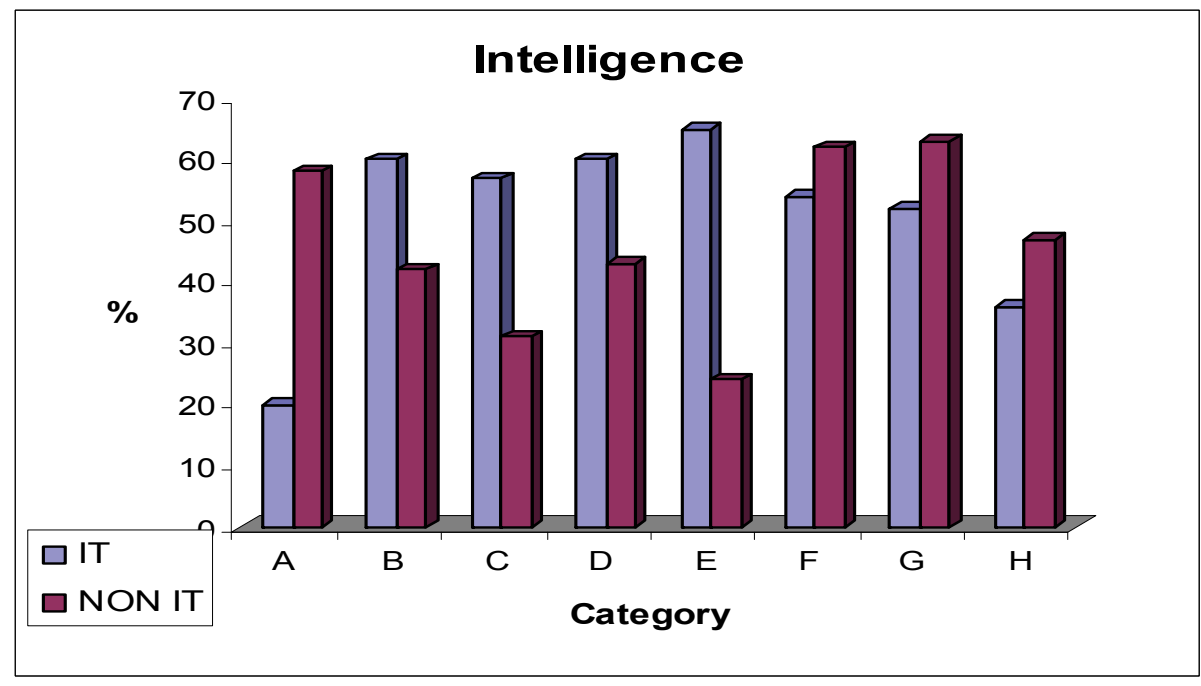

Figure 1. Use of Multiple Intelligences by group...

centage of linguistic intelligence and naturalistic intelligence reveals the importance that the field of information technology to machines and robotics as compared to the natural world. It is any interesting aspect which needs to be further investigated.

Figure 2 summarises the use of the different types of intelligences used by all the students irrespective of their field of study. It appears from an analysis of the distribution of the types of intelligences used, that important use of logical mathematical, body-kinesthetic, interpersonal, intrapersonal intelligences are evident among all students; and to a lower extent spatial and musical intelligences; while linguistic and naturalistic intelligences are at a lower level, with linguistic intelligence at the lowest.

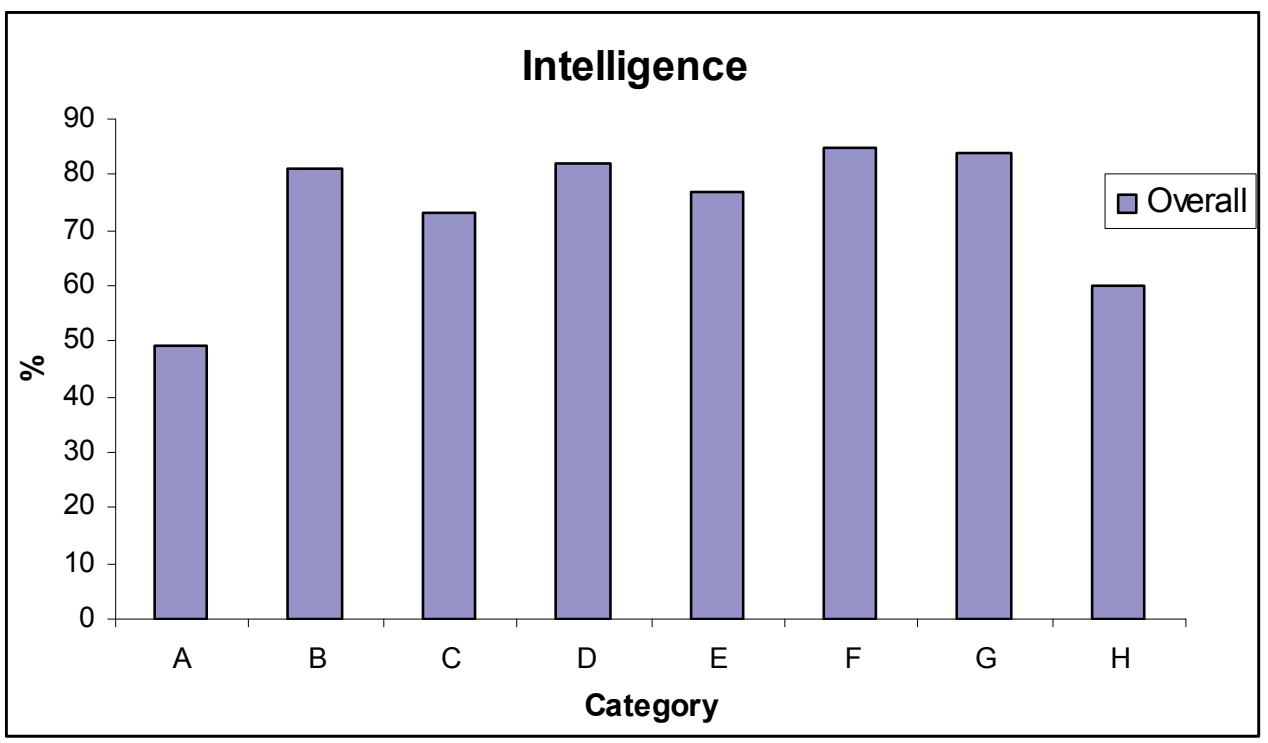

Figure 2 - Use of Multiple Intelligences by the overall group of students

The use of the B - logical-mathematical, C - spatial intelligence, D - body-kinesthetic, E - musical intelligence, $\mathrm{F}$ - interpersonal, $\mathrm{G}$ - intrapersonal, intelligences by the students, irrespective of their fields of study shows that these commonly used intelligences is a clear indication of the 
similarity of the criteria used for proposing assignments/ projects/dissertations to students reading in the two sectors.

The low percentage of linguistic and naturalistic intelligences in the overall graphic representation reflect the influence of a lower use of these two types of intelligences the group of IT students.

Figure 3 presentations show the trends in the use of Multiple Intelligences by each group of student. As it can be observed the differences in the use of each type of intelligence among IT and Non-IT students is quite evident, and shows that intelligences do influence their output in their study activities. The IT group tends to rely more mathematical intelligence, while the Non IT group favours linguistic intelligence. The major discrepancies seem to be in relation to the use of logical-mathematical, spatial, body-kinesthetic, and musical intelligence (where the widest discrepancy lies).

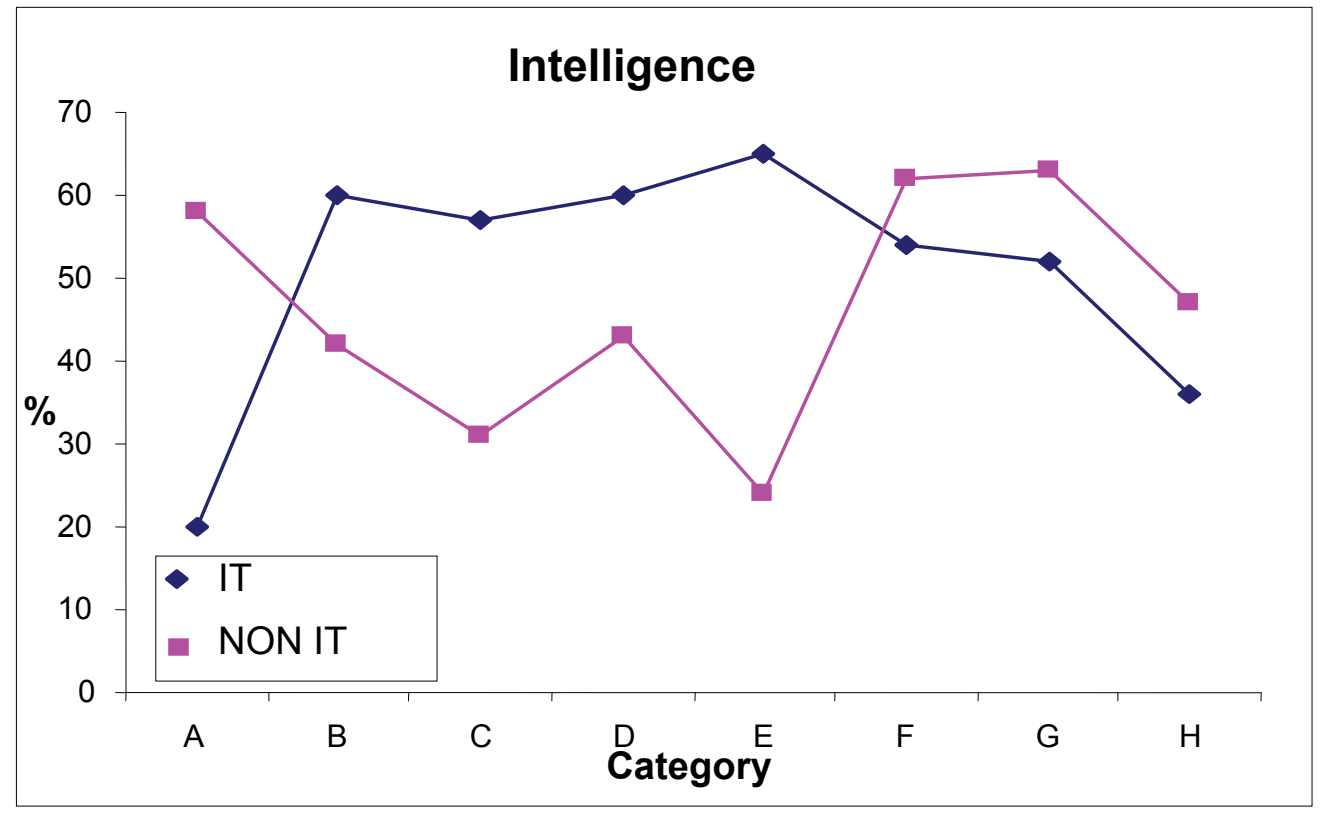

\section{Figure3 - Graph showing the pattern of MI used by students in each group}

There seem to be the same interest for interpersonal and intrapersonal intelligences; and the same disinterest for naturalistic intelligence. The low interest for spatial and musical intelligences among the Non-IT students reflects the lack of form, colour, space and relationships on the one hand, and the absence of sounds, rhythms, and tempo related to the "machine" dimension within their area of study.

Figure 4 shows the overall trend in the use of Multiple Intelligences.

The graphic representation confirms the low interest in linguistic and naturalistic intelligences by the two groups; but does not reflect the nearly $60 \%$ use of linguistic intelligence by the Non-IT group, owing to the low interest of the IT group for this type of intelligence. 


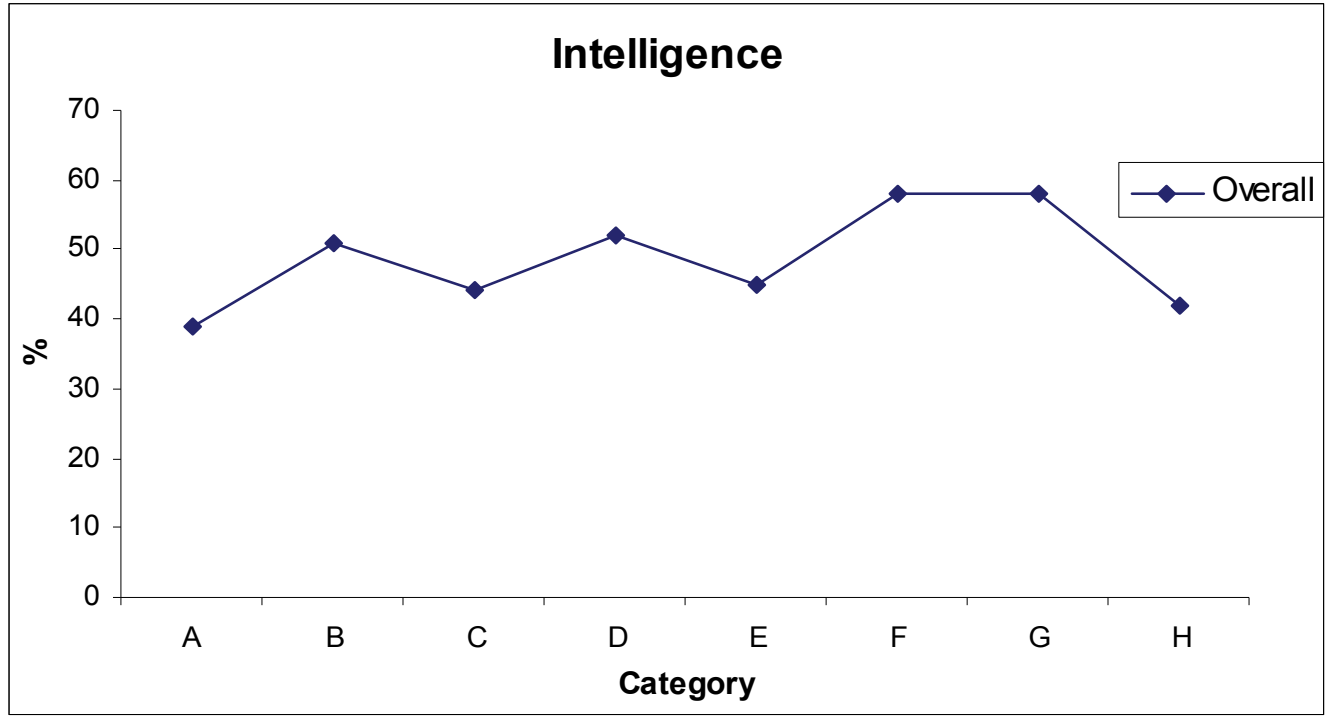

Figure 4 - Graph showing the pattern of MI used by both groups

\section{Use of Soft Skills}

As pointed out in the introduction, the soft skills proposed as being of a certain importance in the realisation of their university studies are denoted in Figure 5 by letters $A-H$,
A - Communication.
E - Time Management.
B - Team Work
F - Trustworthiness
C - Leadership.
$\mathrm{G}-$ Conflict
D - Stress Management.
$\mathrm{H}$ - Organisational Effectiveness

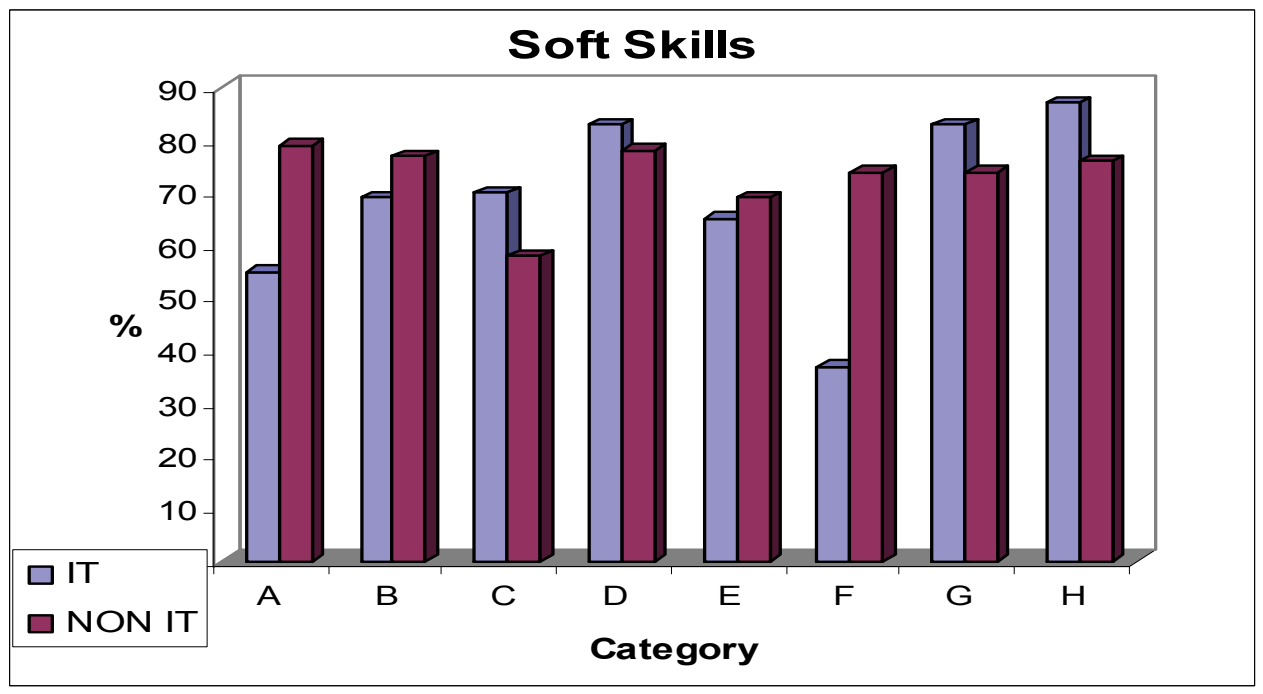

Figure 5 - Importance of Soft Skills

The importance of the use of soft skills is illustrated in Figure 5. The analysis shows that communication skills, team work and trustworthiness are important soft skills used by the Non IT students; while leadership skills, stress management skills, conflict management skills and organisational effectiveness are the important soft skills for the IT students. 
In view of the major role of communication skills and team work in the Non IT areas of study as opposed to the Information Technology Education sector, it seems evident that the most important soft skills for IT students be the ones shown in the diagram.

As the Non-IT students educational activities brings them to work in close collaboration with others and to favour communication and group work, they tend to be less individualistic than their IT colleagues, whose work requires a more self- centered approach based on self awareness and a more mechanistic than organistic approach and creates conflicting situations.

On the other hand IT students tend to rely much on the resources, facilities and learningconducive work environment which the organisation is expected to provide the staff and students with.

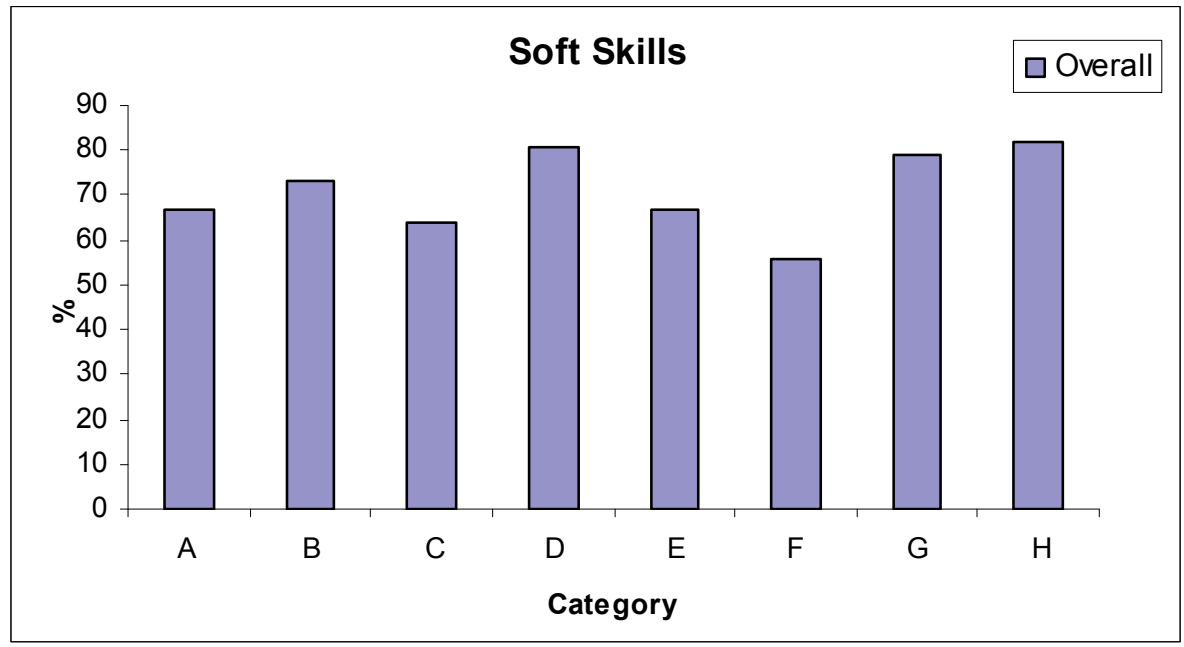

Figure 6 - Soft Skills used by overall group

As shown in Figure 6, the soft skills used by a majority of students involved in the study are: B Team work, D - stress management, $\mathrm{G}$ - conflict management and $\mathrm{H}$ - organisational effectiveness.

These important soft skills used by the students indicate that team work is an important and desirable skill for the successful preparation of projects, but stress management seem to be as important as organisational effectiveness; while conflict management looks to be the third important skill.

Stress management skill, which seems to be the major one used by an important majority of students, reflects how the students respond to the pressure of the system of study proposed by the University.

Figure 7 shows how each group of student have been using soft skills in their academic activities. The marked difference in the use of these skills between the two groups is evident.

The common soft skill used with an important discrepancy by the two groups is communication, and with an even wider gap in trustworthiness as shown in Figure 7. Both groups (see Figure 8) seem to be concerned with team work, leadership skills, time management skills, conflict management skills and organisational effectiveness, but seem to disagree with the use of trust; with the IT group less inclined to accept trustworthiness as an important skill in project preparation and presentation. 


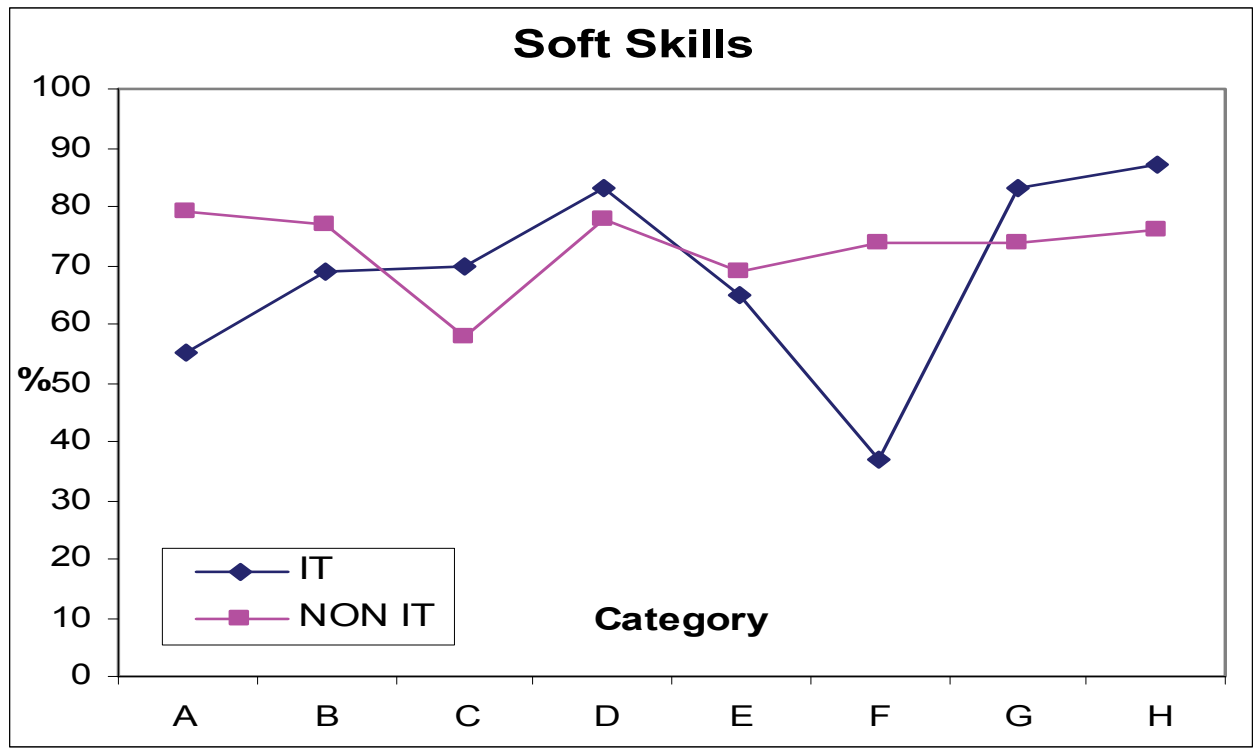

Figure 7 - Graph showing the trend in the use of soft skills by each of the group of students

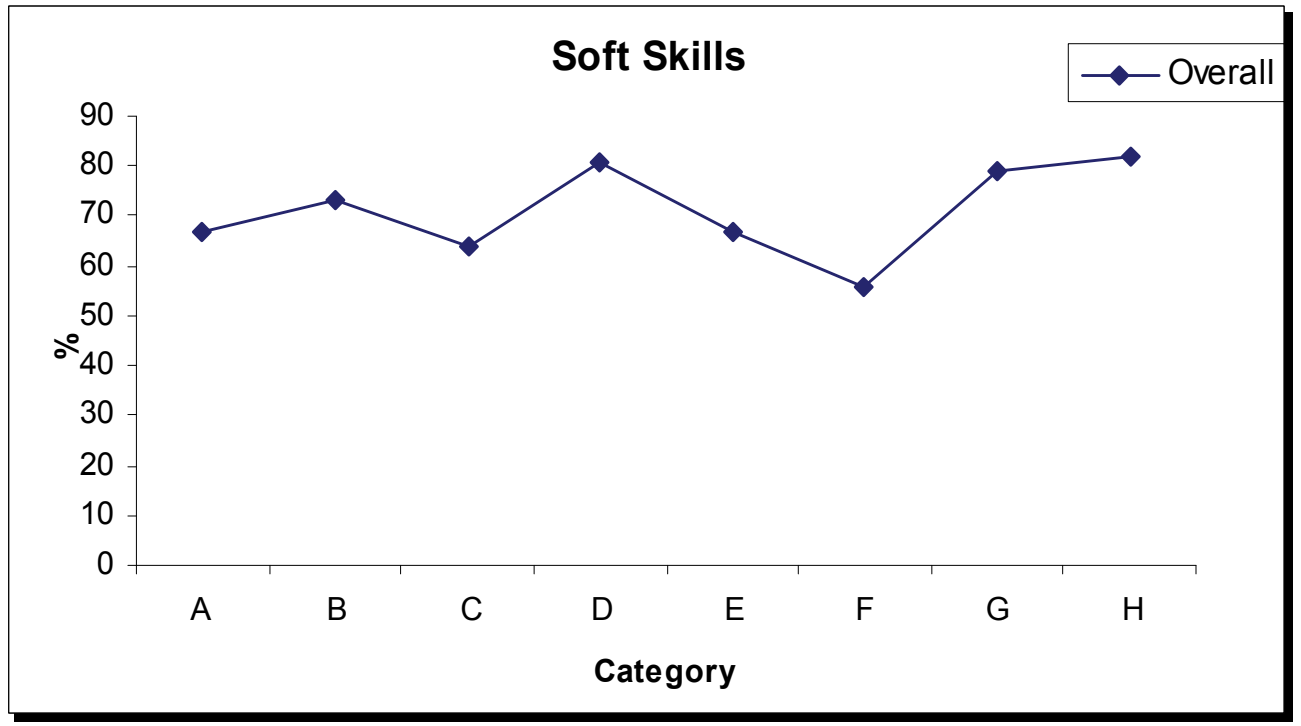

Figure 8 - Graph showing the trend in the use of soft skills by both groups of students.

As a general comment, one can state that soft skills seem to be as important to the IT students as well as for the Non-IT students, with marked differences in the use of certain skills linked with the specificity of the study areas of each group. These differences need to be further investigated to find out causal factors which could later be analysed and solutions proposed as to how to help students use the different types of intelligences and how to acquire the soft skills that can ensure successful student life in all fields of study.

\section{Conclusion}

It has been an interesting and exciting challenge to investigate the influence of multiple intelligences and the use of soft skills among a group of nearly two hundred students. We have tried to look into some issues related to information technology education and other related psychological aspects. There is much to be done to find out the influence of other factors like age, gender, per- 
sonality, culture, academic level, and other psychological, socio-psychological, cognitive, emotional factors on the influence of multiple intelligences and the use of soft skills. The relationships among these factors need to be further investigated. The future research will lead towards getting some answers to our questions, and to further investigate the role of soft skills and other types of intelligences as discussed in the previously mentioned papers.

\section{References}

Armstrong, T, (1994). Multiple intelligences in the classroom. Virginia: Association for Supervision and Curriculum Development.

Belier, K. 92004). Project management: Still more an art than science. Retrieved from http://www.pmforum.org/library/papers

Farago, J. \& Skyrme, D. (1995). The learning organisation. Retrieved from http://www.skyrme.com/insights/3lrnorg.htm

Gardner, H. (1983). Frames of mind: The theory of multiple intelligence. New York, NY: Basic Books.

Gardner, H, (1993). Theory of multiple intelligences. Retrieved 11.27.2006 from http://en.wikipedia.org.wiki/Theory_of multiple_intelligences

Gardner, H, (1999). Intelligence reframed: Multiple intelligences for the $21^{\text {st }}$ century.

Goleman, D. (1995). Emotional intelligence. New York, NY: Bantam Books.

Goleman, D. (1998). Working with emotional intelligence. New York, NY: Bantam Books.

Lussier, R.N (1990). Human relations in organisations: A skill-building approach. Homewood, IL: Irwin.

Mayer, J.D. \& Cobb, C.D. (2000). Educational policy on emotional intelligence: does it make sense? Educational Psychology Review, 27.

Motah, M. (2006). The ontogeny of memory of learning: Natural Intelligence versus Artificial Intelligence in Information Technology Education Proceedings of the 2006 Informing Science and IT Education Joint Conference, p.224. Available at http://proceedings.informingscience.org/InSITE2006/ProcMota237.pdf

Newstrom, J.W, \& Davis K (2002) Organisational behaviour - human behaviour at work. McGraw-Hill Irwin.

Santrock, J.W. (2000). Psychology $\left(6^{\text {th }}\right.$ ed.). McGraw-Hill.

Sukhoo, A., Barnard, A., Eloff, M., Van der Poll, J. A. \& Motah, M. (2005). Accommodating soft skills in Software project Management Issues in Informing Science and Information Technology, p. 691-703. Available at http://2005papers.iisit.org/I55f42Sukh.pdf

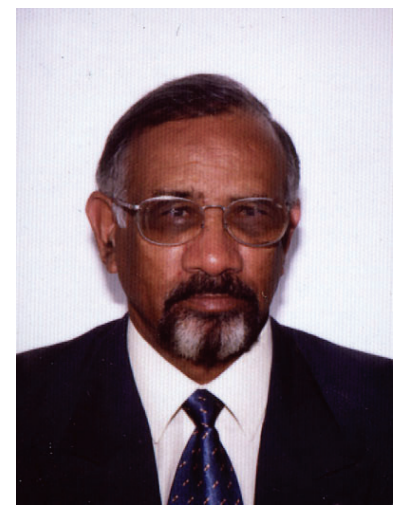

\section{Biography}

Mahendrenath Motah is Senior Lecturer at the University of Technology, Mauritius. He has a Postgraduate Diploma in Educational Psychology from Paris V, Rene Descartes, University; Master's Degrees in Psychology and Ethnology, and a PhD in Arts and Human Sciences from Paris VII, Jussieu University, Paris, France. He has spent three months as a Visitor at Jordanhill College of Education, Glasgow, Scotland in April- July 1985 under the British Council. He has spent one month in USA, as a Visitor under USIA in June 1987. $\mathrm{He}$ also attended the Laurentian University, Sudbury, CANADA in connection with the Distance Education Links Project, under CIDA in June 1995. He has participated in various Workshops, Seminars and Conferences at National and International levels. He has extensive ex- 
perience in the fields of Management, Administration and Training at both National and International levels. He has been Training Manager for an International Hotels and Resorts Company from 1996 - 1998. He has also been Advisor in Psychological Matters for the Ministry of Youth and Sports during the period 1999 - 2000 before joining the University of Technology, Mauritius in April 2000. He is Chairperson of the Regional Centre for Urgent Anthropological and Ethnological Research. His interests are research in the field of education and human Sciences. He has launched a Masters in Educational Administration \& Technology, and is at present working on a Degree course in Counselling.

He has presented the following papers at International Conferences:

Accommodating Soft Skills in Software Project Management - InSITE Conference, June 2005, Flagstaff, Arizona, USA.

The need for a consensual, coherent and comprehensive approach to tourism education in developing countries, with reference to some Indian Ocean Islands - RDTR Conference, Algarve University, Faro, Portugal, October 2005.

The ontogeny of memory and learning: Natural Intelligence versus Artificial Intelligence in Information Technology Education. - InSITE Conference, Salford, UK, June 2006. 